\title{
THE IMPORT OF CAPITAL TAXES AND ENVIRONMENTAL STANDARDS COMPARED TO AGGLOMERATION ON CAPITAL FLOW
}

\author{
Mitch Kunce \\ DouglasMitchell Econometric Consulting Laramie, WY USA
}

Citation: Mitch Kunce (2022) The Import of Capital Taxes and Environmental Standards Compared To Agglomeration on Capital Flow, British Journal of Environmental Sciences, Vol.10, No.2, pp. 51-63

\begin{abstract}
The effect of competition for mobile capital on local (jurisdictional) policy making is critical to the fiscal-environmental federalism literature. This existing body of literature, however, is deficient in examinations of how influential local policy levers, environmental standards and taxation, compare with fundamental capital location determinants like agglomeration forces. The purpose of this investigation is to broaden the agglomeration augmented interjurisdictional competition model to effectively compare local policy and agglomeration influences on capital flow. When jurisdictions do not have access to forms of taxation that allow for the efficiency of public goods provision, agglomeration forces notably impact fiscal policy weight. Herein, the magnitude of agglomeration directly effects the determination of the capital tax rate which in turn influences the provision of public goods. Subsequent inefficient public goods provision will distort the local choice of environmental standards. The capital tax must be complimented by 'benefit' taxation to finance efficient public expenditure. Interestingly, when public goods are provided efficiently, the capital tax doubles as a Pigovian remedy and a subsidy instrument depending, largely, on the strength of agglomeration forces.
\end{abstract}

KEYWORDS: environmental regulation, capital tax competition, agglomeration economies

JEL CLASSIFICATIONS: H72, Q51, R12

\section{INTRODUCTION}

The influence of competition for mobile capital on local policy making is central to the fiscal-environmental federalism literature (Oates 2002). However, traditional interjurisdictional competition models tend to ignore the forces of agglomeration. The importance of agglomeration economies on regional economic growth and the spatial distribution of economic activity is the subject of a vast and accomplished literature (Henderson 1988: Krugman 1991; Glaeser et al 1992). Building on a related strand of new economic geography (NEG) modeling, Baldwin and Krugman (2004) forward that agglomeration economies can in fact tie supposed mobile capital to a jurisdiction. If agglomeration forces are sufficiently strong and local governments possess information

ECRTD-UK https://www.eajournals.org/

Journal level DOI: https://doi.org/10.37745/bjes.2013 
about them, the import of local policy influences on capital flow is weakened. A small literature now exists integrating external economies into the standard tax competition model (see Krogstrup 2008 for a review). In these models, capital mobility is constrained when external economies of scale have strong influences on the net returns to capital.

The existing body of literature, however, is deficient in examinations of how key local policy levers, environmental standards and taxation, compare with fundamental capital location determinants like agglomeration forces. A few studies have evaluated the interaction effects between agglomeration and environmental regulations (e.g. Zeng and Zhao 2009; Pang et al 2021) but these attempts ignore the joint determination of tax policy and environmental standards central to the work of Oates and Schwab (1988). In a more recent paper, Kunce (2022a) incorporates multiplicative external economies into the framework of Oates and Schwab (1988) finding that when external economies to scale are sufficiently strong, local policy influences on capital flow are mitigated providing jurisdictions' incentives to strengthen environmental standards beyond the social optimum. Devolved environmental standard setting is shown to be inefficient but in the 'right direction' for those concerned with enhanced environmental quality. This result hinges on two key modeling assumptions, (i) jurisdictions are limited to source-based capital taxation and inefficiently provide local public goods, and (ii) all pollution externality rents generated are implicitly internalized by immobile residents of a jurisdiction via their endogenously determined wage.

The purpose of this investigation is to broaden the augmented model introduced by Kunce (2022a) to effectively compare local policy and agglomeration influences on capital flow. First, following Oates and Schwab (1991), local jurisdictions are assumed to have access to 'benefit' taxation allowing for more degrees of freedom in setting the tax on mobile capital. This assumption has some basis in fact, local governments do have access to multiple tax sources and many of them have the potential, at least at the margin, to be designed as benefit taxes. Second, allowed pollution emissions are treated as an 'unpaid factor' to firms in direct proportion to their employment of capital (Oates and Schwab 1991). Herein, allowed emission levels act as a public input characterized by the same degree of rivalry as private production factors. ${ }^{1}$ Firms now perceive that the marginal gain in capital investment is equal to the sum of the marginal product of capital and rents generated from allowed pollution emissions.

When jurisdictions operate in a second-best setting, agglomeration forces notably impact the effects of local policy choices. The strength of agglomeration economies directly impact the determination of the capital tax rate which in turn influences efficiency of public goods provision. Resulting suboptimal provision of public goods then distorts the local choice of environmental quality. Benefit taxation is shown to be necessary for the

${ }^{1}$ See Feehan (1989) for a more complete classification of public inputs to production. Kunce and Shogren (2005a) provide a review of firm-augmenting public inputs.

ECRTD-UK https://www.eajournals.org/

Journal level DOI: https://doi.org/10.37745/bjes.2013 
efficient financing of public expenditure and optimal choice of emissions allowed. The balance of this paper is organized as follows. The next section fully develops the augmented model and explores the resulting equilbria. Section three draws implications and concludes.

\section{THE MODEL}

The economy modeled is divided into $J(i=1, \ldots, J)$ symmetric jurisdictions were agglomeration forces are abundant. A single industry exists within each jurisdiction comprised of identical, polluting firms $N_{j}$. Jurisdictions are large enough that firms' pollution externalities are purely localized yet 'small' enough that their policy dealings are deemed 'competitive'. ${ }^{2}$ Industry output, the numeraire, is produced using immobile labor, $L_{j}$, mobile capital, $K_{j}$, and following Oates and Schwab $(1988 ; 1991)$, unpaid emissions, $E_{j}$. The input $E_{j}$ represents an aggregate level of an allowed quantity of pollution concentration in a jurisdiction. Local authorities set $E_{j}$ following a firm summative command and control mechanism. ${ }^{3}$ Higher levels of $E_{j}$ correspond to relaxing environmental standards. In the broader economy, the overall capital stock $\bar{K}$ is fixed with the model concentrating on location choices rather than new capital formation. Additionally, since each jurisdictional resident inelastically supplies one unit of labor, $L_{j}$ represents the jurisdiction's fixed population with the broader population defined as $\bar{L}=\Sigma_{j} L_{j}$. Moreover, each resident owns an equal share, $1 / \bar{L}$, of $\bar{K}$.

Jurisdictional production follows,

$$
Q_{j}=F\left(L_{j}, K_{j}, E_{j}\right) A\left(K_{j}\right),
$$

where each firm produces $\left[1 / N_{j} \cdot F\left(L_{j}, K_{j}, E_{j}\right)\right] A\left(K_{j}\right)$. The last term in equation (1) denotes the multiplicative augmentation to productivity associated with aggregate levels of capital - agglomeration economies. ${ }^{4}$ Assuming $F\left(L_{j}, K_{j}, E_{j}\right)$ is linearly homogeneous in all inputs, using Euler's theorem, production can be written as,

$$
\left[F_{L} L+F_{K} K+F_{E} E\right] A(K)
$$

where subscripts now represent partial derivatives and jurisdictional indexing going forward will be suppressed, though expressions are understood to be jurisdiction specific.

\footnotetext{
${ }^{2}$ This pollution externality fits Oates (2002) classification "Benchmark Case 2: Local Public Goods." See List and Mason (2001) for a model treating transboundary pollution externalities. Jurisdictions are small in the sense that their policy dealings have no effect on the decisions of other jurisdictions. See Kunce (2022b) for a game-theoretic (strategic) model of jurisdictional environmental choice.

${ }^{3}$ See Kunce and Shogren (2002) for a model that considers firm specific emission standards.

${ }^{4}$ See Fernández (2005) and Krogstrup (2008) for a similar constructs.
}

ECRTD-UK https://www.eajournals.org/

Journal level DOI: https://doi.org/10.37745/bjes.2013 
Marginal products of $F(L, K, E)$ are all positive and diminish $F_{L L}, F_{K K}, F_{E E}<0$. External economies are also increasing, $A(K)>1, A_{K}>0$. Individual firms take the aggregate amount of capital as given thus treat $A(K)$ as parametric. As shown in equation (2), the pollution emissions input generates rents of $F_{E} E \cdot A(K)$. Herein, we treat these rents as stemming from an 'unpaid factor' benefiting firms in proportion to their capital employment (see Oates and Schwab 1991). Rent rationing is defined as,

$$
R=\frac{1}{K} F_{E}(L, K, E) \cdot E \cdot A(K)=\frac{1}{K} F_{E} E A .
$$

The condition for profit maximizing capital investment becomes,

$$
r=F_{K} A+R-t
$$

where $t$ is a source-based unit tax. Profit maximizing forces distribute capital until $r$, the net return to capital, is equalized across all jurisdictions. Competitive firms and 'small' jurisdictions view $r$ as exogenous. Additionally, firms pay the immobile labor input an endogenously determined wage less a free-to-vary head (benefit) tax, $h$,

$$
w=F_{L} A-h,
$$

correspondingly using equations (1) and (2),

$$
F_{L} A=\frac{1}{L}\left(F A-F_{K} K A-F_{E} E A\right)
$$

Each jurisdiction finances a local Samuelsonian public good with a combination of benefit and capital taxes where,

$$
G=h L+t K
$$

Taxing the fixed factor (labor) in this manner insures the efficient provision of $G$ (Kunce 2000). This approach, convention in the vast tax competition literature, suggests local governments believe that private production is sufficiently capital intensive and attempt to stimulate capital investment by lowering capital tax rates (Wilson 1986). Herein, capital taxation along with environmental standards become the key policy levers available to jurisdictions attempting to influence capital flow.

The representative resident's total income can now be defined,

ECRTD-UK https://www.eajournals.org/ 


$$
x=\frac{1}{L}\left(F A-F_{K} K A-F_{E} E A\right)+\frac{r \bar{K}}{\bar{L}},
$$

or when using equations (3) through (5) and (7),

$$
x=\frac{1}{L}(F A-r K-G)+\frac{r \bar{K}}{\bar{L}},
$$

where the far right term denotes a per capita share of returns to ownership of $\bar{K}$.

Identical residents of a jurisdiction receive utility from consumption and local public goods, but suffer disutility from the level of allowed pollution emissions. A jurisdictional representative resident's utility takes the form, $U(x, G, E)$, where $U$ is quasi-concave with $U_{x}, U_{G}>0$, but $U_{E}<0$. Higher $E$ corresponds to poorer environmental quality where $E$ represents a pure public bad. In keeping with the Arrow-Debreu (Wilson 1999) separation assumption for general equilibrium constructs, residents have two distinct roles in the model. First, as consumers, they seek to maximize utility over a bundle of goods and public services. Second, supplying labor inputs and in return receiving income for consumption. More industry resource certainly enhances local production and can provide residents with higher incomes hence more consumption. However, in order to attract the mobile resources, the jurisdiction lowers taxes (effecting $G$ ) and/or relaxes environmental regulations (lowering utility directly) thus setting up a characteristic economic tradeoff.

Will competition among small jurisdictions with agglomeration forces lead to efficiency? Social efficiency requires the maximization of the representative resident's utility subject to (i) utility in all other jurisdictions is equalized to a fixed level, (ii) aggregate production and consumption clear, and (iii) the mobile firm and capital stock is allocated entirely among jurisdictions (clear). The resulting benchmark social optimum conditions from the standard model (without agglomeration) are well known (see Oates and Schwab 1988; Wilson 1999) therefore derivation discussion is keep to a minimum. Traditional model social efficiency rules are defined,

$$
\begin{aligned}
& L \frac{U_{G}}{U_{x}}=1 \quad \forall j \text { jurisdictions, } \\
& L \frac{-U_{E}}{U_{x}}=F_{E} \quad \forall j .
\end{aligned}
$$

Equation (10) represents the familiar 'Samuelson condition' for the provision of public goods (Wilson 1986). This appropriate optimality condition suggests that the marginal rate of substitution (summed over all residents) between the public good and

ECRTD-UK https://www.eajournals.org/

Journal level DOI: https://doi.org/10.37745/bjes.2013 
consumption equals the marginal cost of providing an incremental increase in the public good. Given equation (9), the marginal rate of transformation in this context is one for one. Equation (11) shows that jurisdictions should choose a combination of environmental quality and consumption such that the marginal rate of substitution (summed over all residents) between the two equals the marginal product of emissions (recall that $\left.U_{E}<0\right){ }^{5}$ Equation (11) then represents a Samuelson rule for environmental quality, if you will (Kunce and Shogren 2005b).

Jurisdictional authorities, taking into account the presence of external economies, choose over a policy variable vector $\theta=\{h, t, E\}$ that maximizes the representative resident's utility subject to equations (7) and (9). First order conditions become,

$$
\frac{U_{G}}{U_{x}} \frac{\partial G}{\partial \theta}+\frac{U_{E}}{U_{x}} \frac{\partial E}{\partial \theta}+\frac{\partial x}{\partial \theta}=0
$$

where,

$$
\frac{\partial G}{\partial \theta}=L \frac{\partial h}{\partial \theta}+t \frac{\partial K}{\partial \theta}+K \frac{\partial t}{\partial \theta}
$$

noting that $L$ is fixed, and using equation (4),

$$
\frac{\partial x}{\partial \theta}=\frac{1}{L}\left[F A_{K} \frac{\partial K}{\partial \theta}+t \frac{\partial K}{\partial \theta}+A F_{E} \frac{\partial E}{\partial \theta}-R \frac{\partial K}{\partial \theta}-\frac{\partial G}{\partial \theta}\right]
$$

Equations (3) and (4) provide the necessary system required to determine $K$ as an implicit function of each policy variable in $\theta$. This system yields the relevant comparisons needed to complete and interpret the first order conditions. Proceeding first with head tax effects,

$$
\frac{\partial K}{\partial h}=0
$$

reflecting that taxing the fixed factor has no direct effect on capital flow. Continuing with the effects of capital taxation, from equation (3),

$$
\frac{\partial R}{\partial K}=\frac{E K\left(F_{E} A_{K}+A F_{K E}\right)-A F_{E} E}{K^{2}}=\Omega_{2}
$$

\footnotetext{
${ }^{5}$ Alternatively, given production with a scalar constant, $\bar{A} F(L, K, E)$, the marginal product with respect to emissions becomes $\bar{A} F_{E}$. Herein, firms treat $A(K)$ as parametric.
}

ECRTD-UK https://www.eajournals.org/ 
where equation (16) reflects how emission rents change with marginal changes in capital employed. A complementary relationship between capital and allowed emissions, $F_{K E}>$ 0 , is a requisite and natural assumption given the aggregation in local production. ${ }^{6}$ Note that strong agglomeration forces $\left(A_{K}\right)$ at the margin coupled with capital-emissions complementarity provide the conditions necessary for equation (16) to be signed positive. From equation (4),

$$
\frac{\partial\left(A F_{K}\right)}{\partial K}=\left(F_{K} A_{K}+A F_{K K}\right)=\Omega_{1}
$$

where equation (17) denotes how the marginal product of capital changes with marginal perturbations in capital employed. If decreasing marginal productivity of capital, $A F_{K K}$, dominates the external economies to scale, $F_{K} A_{K}$, equation (17) is negative. Krogstrup (2008) refers to this result as "agglomeration forces of moderate strength." When agglomeration forces have a stronger influence on the marginal product of capital, equation (17) will be positive.

Using the implicit function theorem and equations (4), (16) and (17),

$$
\frac{\partial K}{\partial t}=\frac{1}{\Omega_{1}+\Omega_{2}},
$$

where strong external economies to scale will tend to subordinate local tax policy effects on capital flow. Specifically, when agglomeration forces are sufficiently strong, the denominator of equation (18) is positive where increases in $t$ do not deflect capital away from a jurisdiction. Lastly, examining how capital responds to changes in $E$,

$$
\frac{\partial K}{\partial E}=\frac{-\left(A F_{K E}+\frac{A}{K}\left(F_{E}+E F_{E E}\right)\right)}{\Omega_{1}+\Omega_{2}},
$$

where a new term appears in the numerator of equation (19), $\left(F_{E}+E F_{E E}\right)$, which depicts the change in emission rents with marginal changes in emissions allowed. A natural assumption is that this change is positive. Interestingly, equation (19) shows that sufficiently strong agglomeration forces, again, overwhelm local policy influence. With strong external economies to scale, capital-emissions complementarity and emission rents

\footnotetext{
${ }^{6}$ See appendix equations (A1) through (A4) for a description of the conditions requiring this cross-partial, $F_{K E}$, to be signed positive.
}

ECRTD-UK https://www.eajournals.org/

Journal level DOI: https://doi.org/10.37745/bjes.2013 
increasing in $E$, jurisdictions lack influence to attract capital with lax environmental standards.

Substituting equations (13) through (19) into equation (12) yields more complete first order conditions, with suitable rearrangement,

$$
\theta=h: \quad L \frac{U_{G}}{U_{x}}-1=0,
$$

using the equation (20) result going forward,

$$
\begin{gathered}
\theta=t: \quad F A_{K}\left(\frac{1}{\Omega_{1}+\Omega_{2}}\right)+t\left(\frac{1}{\Omega_{1}+\Omega_{2}}\right)-R\left(\frac{1}{\Omega_{1}+\Omega_{2}}\right)=0 \\
\theta=E: \quad L \frac{U_{E}}{U_{x}}+A F_{E}-F A_{K} \frac{\left(A F_{K E}+\frac{A}{K}\left(F_{E}+E F_{E E}\right)\right)}{\Omega_{1}+\Omega_{2}}-t \frac{\left(A F_{K E}+\frac{A}{K}\left(F_{E}+E F_{E E}\right)\right)}{\Omega_{1}+\Omega_{2}} \\
+R \frac{\left(A F_{K E}+\frac{A}{K}\left(F_{E}+E F_{E E}\right)\right)}{\Omega_{1}+\Omega_{2}}=0 .
\end{gathered}
$$

Solving equations (21) and (22) simultaneously yields the optimal conditions,

$$
\begin{aligned}
& t=R-F A_{K}, \\
& L \frac{-U_{E}}{U_{x}}=A F_{E} .
\end{aligned}
$$

From equation (23), jurisdictions can exploit their efficiently provided public goods base by taxing $\left(t>0\right.$ when $\left.R>F A_{K}\right)$, not taxing $\left(t=0\right.$ when $\left.R=F A_{K}\right)$ or subsidizing $(t<0$ when $R<F A_{K}$ ) capital. External economies directly effect the choice of $t$ in the optimal condition. When agglomeration forces are weak to moderate and emission rents dominate the right-hand-side of equation (23), capital taxation behaves as a Pigovian remedy, at the margin, internalizing net emissions rents. If agglomeration economies are strong, capital movement becomes 'sticky' and jurisdictions may choose to subsidize capital in order to influence flow from other jurisdictions. Equation (24) shows that jurisdictions will choose a combination of emission concentration and consumption where the marginal rate of substitution between the two (summed over all residents) is

ECRTD-UK https://www.eajournals.org/

Journal level DOI: https://doi.org/10.37745/bjes.2013 
equal to the marginal product of allowed emissions (note that firms view $A$ as a parameter). In this equilibrium, local authorities choose not to influence capital flow with suboptimal environmental standards and external economies play no direct role in the optimal choice rule.

At this point, it is important to address how a jurisdiction's fiscal structure is intertwined with it's choice of environmental quality. One way to establish this is to rule out benefit taxation for jurisdictions. The Appendix to this paper reworks the model with the public good being financed entirely by taxing capital. The resulting optimal conditions are presented in equations (25) and (26),

$$
\begin{aligned}
& t=\left(R-F A_{K}\right)\left(\frac{1}{L \frac{U_{G}}{U_{x}}}\right)-\left(\Omega_{1}+\Omega_{2}\right) K\left(1-\frac{1}{L \frac{U_{G}}{U_{x}}}\right), \\
& L \frac{-U_{E}}{U_{x}}=A F_{E}\left(L \frac{U_{G}}{U_{x}}\right)-A L F_{L E}\left(L \frac{U_{G}}{U_{x}}-1\right) .
\end{aligned}
$$

As shown, public goods provision appears as a central term in each optimal condition. Suboptimal provision, joined with agglomeration and production relationships, leads to multiple case scenarios regarding the choice of $t$ and $E$. Interior solution constraints define bounds for the value of the marginal rate of substitution between public goods and consumption where,

$$
1>L \frac{U_{G}}{U_{x}}>0 \text {, overprovision and, } L \frac{U_{G}}{U_{x}}>1 \text {, underprovision . }
$$

Of course, efficient provision yields equations (23) and (24). Focusing on equation (25), a meaningful (interior) solution requires a positive tax rate, $t$. Also note that agglomeration forces directly impact the terms, $F A_{K}, \Omega_{1}$ and $\Omega_{2}$. Conceding that many cases may determine a meaningful solution for $t$, two examples appear noteworthy. First, assuming that taxing capital, under weak to moderate external economies, leads to the underprovision of public goods (akin to Wilson 1986) and emission rents exceed agglomeration effects at the margin, equation (25) yields an unambiguous interior solution. Alternatively, assuming sufficiently strong external economies, the term $R$ $F A_{K}$ not significant in magnitude and taxing 'sticky' capital leads to the overprovision of public goods, $t$ again is positive.

ECRTD-UK https://www.eajournals.org/ 
Applying the same two case scenarios to equation (26), the underprovision of public goods coupled with labor-emissions substitutability ${ }^{7}$ would lead local authorities to set lax environmental standards. Specifically, the marginal rate of substitution between emission concentration and consumption exceeds the marginal product of emissions hence jurisdictions would choose a higher level of $E$ compared to the social optimum. Under the second case, taxing 'sticky' capital resulting in the overprovision of public goods would provide jurisdictions the incentive to set $E$ lower than the social optimum. Now, the marginal product of emissions is greater than the marginal rate of substitution between allowed emission levels and consumption. With strong agglomeration forces at work, capital flight is not a key concern when setting tougher local environmental regulations.

\section{CONCLUDING REMARKS}

Arguably the most important policy-relevant insight generated by the NEG literature is that strong agglomeration forces significantly impact the mobility of capital (Baldwin and Krugman 2004). This insight has put into question the effectiveness of local government policy influences on capital flow. In effect, fiscal competition pressures are subdued when sufficiently strong external economies are present. What seems to be missing in the analysis, however, is an understanding of the interconnection of local policy levers and capital agglomeration. Results herein hopefully shed some much needed light. When jurisdictions do not have access to forms of taxation that allow for efficiency of public goods provision, agglomeration forces notably impact fiscal policy weight. As shown, the magnitude of agglomeration directly effects the determination of the capital tax rate which in turn influences the provision of public goods. Subsequent inefficient public goods provision then distorts the local choice of environmental standards.

Other production relationships play a role in determining optimal local policy - herein, the production relationship between labor and allowed emissions and the treatment of emission rents are forefront. The impact of how marginal productivity of labor changes with changes in allowed emissions is determined, largely, by production properties and curvature constraints. Moreover, treating allowed pollution emissions as an 'unpaid factor', generating rents to capital, reveals that sourced-based capital taxation alone does not yield efficiency. The capital tax must be complimented by benefit taxation to finance efficient public expenditure (Garcia-Milà and McGuire 2001) which leads to the optimal choice of environmental quality. Interestingly, when public goods are provided efficiently, the capital tax doubles as a Pigovian remedy and a subsidy instrument depending, largely, on the strength of agglomeration forces.

\footnotetext{
${ }^{7}$ See appendix equations (A1) through (A4) for a description of the conditions requiring this cross-partial, $F_{L E}$, to be signed negative.
}

ECRTD-UK https://www.eajournals.org/

Journal level DOI: https://doi.org/10.37745/bjes.2013 
By introducing external agglomeration forces linked to increasing returns to scale, local policy interdependencies are compounded and more complex. When agglomeration forces are sufficiently strong, jurisdictions can tax more and set stricter environmental standards without fear of capital flight. Firms accept and bear higher taxes and tougher regulatory standards in order to benefit from local agglomeration economies. The import of local fiscal and regulatory policy compared to agglomeration clearly depends on the level of economic integration (Krogstrup 2008) and a jurisdiction's access to nondistortionary fiscal instruments.

\section{REFERENCES}

Baldwin, R. and Krugman, P. (2004) Agglomeration, integration and tax harmonisation. European Economic Review 48, 1-23.

Feehan, J. (1989) Pareto-efficiency with three varieties of public input. Public Finance 44, 237-248.

Fernández, G. (2005) A note on tax competition in the presence of agglomeration economies. Regional Science and Urban Economics 35, 837-847.

Garcia-Milà, T. and McGuire, T. (2001) Tax incentives and the city. Paper prepared for the Brookings-Wharton conference on urban affairs, Washington, DC.

Glaeser, E., Kallal, H., Scheinkman, J., and Shleifer, A. (1992) Growth in cities. Journal of Political Economy 36, 117-143.

Henderson, J. (1988) Urban Development. Theory, Fact and Illusion. Oxford University Press.

Krogstrup, S. (2008) Standard tax competition and increasing returns. Journal of Public Economic Theory 10(4), 547-561.

Krugman, P. (1991) Increasing returns and economic geography. Journal of Political Economy 99, 483-499.

Kunce, M. (2000) A Nash tax Game extending the generality of the Henry George theorem. Economics Letters 66(2), 229-233.

Kunce, M. and Shogren, J. (2002) On environmental federalism and direct emission control. Journal of Urban Economics 51, 238-245.

Kunce, M. and Shogren, J. (2005a) On efficiency of decentralized environmental regulation. Journal of Regulatory Economics 28(2), pp. 129-140.

Kunce, M. and Shogren, J. (2005b) On interjurisdictional competition and environmental federalsim. Journal of Environmental Economics and Management 50, 212-224.

Kunce, M. (2022a) Decentralized environmental regulation with agglomeration forces. Business \& Entrepreneurship Journal 11(1), 27-36.

Kunce, M. (2022b) Efficient decentralized environmental standards from a model of strategic interjurisdictional competition. British Journal of Environmental Sciences 10(1), 1-12.

List, J. and Mason, C. (2001) Optimal institutional arrangements for transboundary pollutants in a second-best world: Evidence from a differential game with

ECRTD-UK https://www.eajournals.org/

Journal level DOI: https://doi.org/10.37745/bjes.2013 
asymmetric players. Journal of Environmental Economics and Management 42, 277-296.

Oates, W. (2002) A reconsideration of environmental federalism, in Recent Advances in

Environmental Economics, Eds: J. A. List and A. de Zeeuw, Edward Elgar Publishing: UK, pp. 1-32.

Oates, W. and Schwab, R. (1988) Economic competition among jurisdictions: Efficiency enhancing or distortion inducing. Journal of Public Economics 35, 333-354.

Oates, W. and Schwab, R. (1991) The allocatitive and distributed implications of local fiscal competition. Reprinted in: Environmental policy and fiscal federalism, selected essays of Wallace E. Oates. 2004. Edward Elgar Publishing.

Pang, R., Zheng, D. and Shi, M. (2021) Agglomeration externalities and the nonlinear performance of environmental regulation. Growth and Change 52(3), 1701-1731.

Wilson, J. (1986) A theory of interregional tax competition. Journal of Urban Economics 19, 296-315.

Wilson, J. (1999) Theories of tax competition. National Tax Journal 52, pp. 269-304.

Zeng, D. and Zhao, L. (2009) Pollution havens and industrial agglomeration. Journal of Environmental Economics and Management 58(2), 141-153.

\section{APPENDIX}

Strict concavity of production, $F(L, K, E)$, requires,

$$
F_{L L} F_{K K}-F_{K L}^{2}>0
$$

and,

$$
2 F_{K L} F_{K E} F_{L E}-F_{L L} F_{K E}^{2}-F_{K K} F_{L E}^{2}+F_{E E}\left(F_{L L} F_{K K}-F_{K L}^{2}\right)<0
$$

The first term in equation (A2) is ambiguous in sign yet would support the inequality constraint if it was negative. Of the three cross-partials in the term, assuming that labor and emissions are technical substitutes appears reasoned and natural $\left(F_{L E}<0\right)$. Capitallabor and capital-emissions are presumed technical complements.

Given that production is linearly homogeneous in all inputs, using Euler's theorem, production can be written as,

$$
F(L, K, E)=F_{L} L+F_{K} K+F_{E} E
$$

where differentiating equation (A3) with respect to $\Phi=\{L, K, E\}$ yields,

$$
L F_{L \Phi}+K F_{K \Phi}+E F_{E \Phi}=0
$$

ECRTD-UK https://www.eajournals.org/

Journal level DOI: https://doi.org/10.37745/bjes.2013 
British Journal of Environmental Sciences

Vol.10, No.2, pp. 51-63, 2022

Print ISSN: 2056351 (print),

Online ISSN: 2054-636X (online)

thus reinforcing $F_{K L}$ and $F_{K E}>0$, when $F_{L E}<0$.

Now suppose that public goods are financed with capital taxes only,

$$
G=t K \text {. }
$$

By substituting equations (13) through (19) into equation (12) from the text yields the expanded first order conditions,

$\theta=t:$

$\left(L \frac{U_{G}}{U_{x}}-1\right)\left(t\left(\frac{1}{\Omega_{1}+\Omega_{2}}\right)+K\right)+F A_{K}\left(\frac{1}{\Omega_{1}+\Omega_{2}}\right)+t\left(\frac{1}{\Omega_{1}+\Omega_{2}}\right)-R\left(\frac{1}{\Omega_{1}+\Omega_{2}}\right)=0$,

$\theta=E$ :

$$
\begin{aligned}
\left(L \frac{U_{G}}{U_{x}}-1\right)\left(t \frac{-\left(A F_{K E}+\frac{A}{K}\left(F_{E}+E F_{E E}\right)\right)}{\Omega_{1}+\Omega_{2}}\right)+L \frac{U_{E}}{U_{x}}+A F_{E}-F A_{K} \frac{\left(A F_{K E}+\frac{A}{K}\left(F_{E}+E F_{E E}\right)\right)}{\Omega_{1}+\Omega_{2}} \\
-t \frac{\left(A F_{K E}+\frac{A}{K}\left(F_{E}+E F_{E E}\right)\right)}{\Omega_{1}+\Omega_{2}}+R \frac{\left(A F_{K E}+\frac{A}{K}\left(F_{E}+E F_{E E}\right)\right)}{\Omega_{1}+\Omega_{2}}=0
\end{aligned}
$$

Solving (A6) and (A7) simultaneously, using equation (A4), yields the optimal conditions, with suitable rearrangement,

$$
\begin{aligned}
& t=\left(R-F A_{K}\right)\left(\frac{1}{L \frac{U_{G}}{U_{x}}}\right)-\left(\Omega_{1}+\Omega_{2}\right) K\left(1-\frac{1}{L \frac{U_{G}}{U_{x}}}\right), \\
& L \frac{-U_{E}}{U_{x}}=A F_{E}\left(L \frac{U_{G}}{U_{x}}\right)-A L F_{L E}\left(L \frac{U_{G}}{U_{x}}-1\right) .
\end{aligned}
$$

ECRTD-UK https://www.eajournals.org/ 